\title{
Application of a non-ionic bio-surfactant instead of chemical additives for prevention of the permeability impairment of a swelling sandstone oil reservoir
}

\author{
Farnam Razzaghi-Koolaee ${ }^{1}$. Ghasem Zargar ${ }^{1}$ - Bahram Soltani Soulgani ${ }^{1}$. Parviz Mehrabianfar ${ }^{1,2}$
}

Received: 27 August 2021 / Accepted: 2 December 2021 / Published online: 11 December 2021

(c) The Author(s) 2021

\begin{abstract}
Formation damage is a general term, which refers to any process that reduces the production or injectivity of an oil well. Clay swelling formation damage, due to incompatible fluid invasion, is a common problem in the petroleum industry. In this research, the effect of Acanthophyllum root extract (ACRE), a bio-based surfactant, on the reduction in reservoir permeability impairment has been studied. Some static tests were applied to investigate the chemical interaction between the surfactant and montmorillonite (Mt), including Mt sedimentation test, Free swelling index (FSI) test, Zeta potential tests, particle size measurement, and scanning electron microscopy (SEM). Experiments were followed by coreflood and micromodel tests to verify their effect on preventing permeability reduction and pore plugging in porous media. According to the results, Mt dispersion is unstable in the presence of $A C R E$ solution. ACRE can reduce the FSI from 233.3 (totally hydrated Mt) to $94.3 \%$, representing the reduction in hydration potential. The zeta potential of $\mathrm{Mt}$ in ACRE aqueous solution moves toward the lowest magnitude, implying that the water molecules surrounding the Mt particles are unstable. Particle size measurement and SEM analysis proved simultaneously that ACRE solution sustains Mt particles flocculated and prevents delamination. The thermal stability of the ACRE was evaluated by thermogravimetric analysis (TGA), and it showed a suitable resistance to the temperature rise. Eventually, coreflood and micromodel tests revealed that ACRE has a high performance in lowering the permeability impairment and pore plugging. All in all, ACRE showed high potential in preventing Mt swelling and, therefore, formation damage in clay-bearing sandstones.
\end{abstract}

Keywords Clay swelling $\cdot$ Montmorillonite $\cdot$ Formation damage $\cdot$ Porous media $\cdot$ Bio-based surfactant $\cdot$ Acanthophyllum root extract

\begin{tabular}{|c|c|c|}
\hline \multicolumn{3}{|c|}{ Abbreviations } \\
\hline \multicolumn{2}{|c|}{ Mt } & Montmorillonite \\
\hline \multicolumn{2}{|c|}{ Surfactant } & Surface Active Agent \\
\hline \multicolumn{2}{|c|}{ ACRE } & Acanthophyllum root extract \\
\hline \multicolumn{2}{|c|}{ SEM } & Scanning Electron Microscopy \\
\hline \multicolumn{2}{|c|}{ CMC } & Critical Micelles Concentration \\
\hline \multicolumn{2}{|c|}{$\mathrm{NaCl}$} & Sodium Chloride \\
\hline \multicolumn{2}{|c|}{$\mathrm{KCl}$} & Potassium Chloride \\
\hline \multicolumn{2}{|c|}{ XRD } & X-Ray Diffraction \\
\hline \multicolumn{3}{|c|}{$\begin{array}{l}\text { Ghasem Zargar } \\
\text { Zargar@put.ac.ir }\end{array}$} \\
\hline \multicolumn{3}{|c|}{$\begin{array}{l}\text { Department of Petroleum Engineering, Ahvaz Faculty } \\
\text { of Petroleum, Petroleum University of Technology (PUT), } \\
\text { Ahvaz, Iran }\end{array}$} \\
\hline \multicolumn{3}{|c|}{$\begin{array}{l}2 \text { Department of Petroleum Engineering, Headquarter } \\
\text { of National Iranian South Oil Company (NISOC), Ahvaz, } \\
\text { Iran }\end{array}$} \\
\hline
\end{tabular}

$\begin{array}{ll}\text { PPI } & \text { Pore Plug Index } \\ \text { FT-IR } & \text { Fourier transform infrared spectroscopy } \\ \text { FSI } & \text { Free Swelling Index } \\ \text { mD } & \text { Milli Darcy } \\ \text { D.W } & \text { Deionized Water } \\ \text { EOR } & \text { Enhanced Oil Recovery }\end{array}$

Introduction

Formation damage is a general term, which refers to any permeability reduction within the vicinity of the petroleumbearing sections of reservoirs caused by different operational processes. This adverse phenomenon can occur during each stage of reservoir development, such as drilling, completion, production, workover. (Mohsenzadeh et al. 2015; Nooripoor and Hashemi 2020; Khilar and Fogler 1984; Bennion et al. 1995). As declared by Amaefule et al. (1988) "Formation

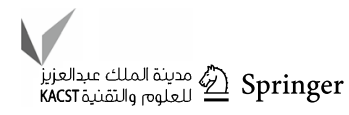


damage is an expensive headache to the oil and gas industry." Evaluating, controlling, and treatment of formation damage are among the pivotal problems, which should be considered to exploit hydrocarbon more efficiently. Probable causes of formation damages include chemical, physiochemical, hydrodynamic, biological, thermal interplay of formation rock and fluids, and the mechanical deformation of formation under stress and fluid shear. (Civan 2007)

Clay minerals are found in the majority of oil and gas reservoirs (Sameni et al. 2015). Clay minerals are layer silicates resulting from the chemical weathering of other silicate minerals on the earth's surface (Wilson et al. 2014). They are the main constituent of the shale, the most abundant sedimentary rock. There are five main clay minerals: kaolinite, smectite, illite, vermiculite, and chlorite. Although various forms of clay exist in the reservoir, the most frequently encountered clays in the reservoir are kaolinite, illite, and smectite. Sodium-saturated smectite (montmorillonite) possesses great potential to swell among all other types of clays. Montmorillonite (Mt) is one of the most abundant clay minerals in petroleum-bearing reservoirs, predominantly sandstones. Due to its high swelling capacity, it has an overwhelming impact on the quality of the reservoir rock. $\mathrm{Mt}$ is composed of a sequence of TOT layers, including an octahedral sheet $(\mathrm{O})$ placed among two tetrahedral sheets (T) (Al-Ani and Sarapää 2008). Because of isomorphous substitution, replacing structural cations of higher valence with lower valance cations, Mt surface carries a net negative charge (He 2020; Leroy et al. 2015; Salles et al. 2007).

There are two kinds of clay swelling mechanisms: crystalline swelling and osmotic swelling (Stamatakis et al. 2007; Fink et al. 1968). Types and amounts of clay minerals present in reservoir rock dictate swelling (Madsen and MüllerVonmoos 1989; Mohan et al. 1999; Norrish 1954).

Any fluid invading through the reservoir can disturb the preexisted equilibrium condition. Formation damage due to swelling of clays, pore blocking because of fine migration, and dislodging of clay particles may occur when foreign fluids permeate a clay-rich reservoir (Foster 1954). Swelling of the clay minerals can be diminished in three manners: coating of clay particles, ion exchange, and alteration of surface chemistry to water-wetness. (Mozaffari et al. 2015) Swelling clays including smectites (montmorillonite) can expand up to 20 times their primary volume as they come into contact with invaded fluids. Therefore, the porosity and permeability would reduce. Based on Fig. 1, the migration may also occur resulting from a high swelling rate and the pore and throats can be blocked. (Mooney et al. 1952; Sharifipour et al. 2017) Oil-based drilling fluids are adequate for penetration into the clay-rich formations because they inhibit clay hydration. Moreover, oil-based drilling fluids have more benefits such as borehole stability, lubricating, corrosion inhibition. Nevertheless, due to the toxicity of these types of drilling

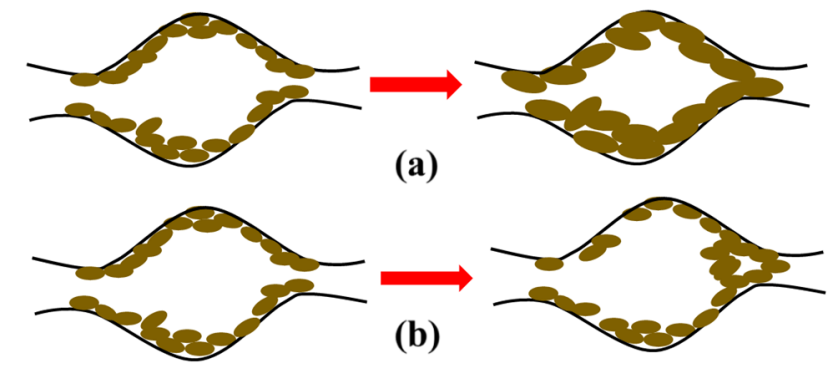

Fig. 1 Formation damage mechanism caused by a swelling and $\mathbf{b}$ migration

fluids, their application is restricted by environmental regulations (Zaltoun and Berton 1992). Therefore, managing and designing water-based mud with properties like oil-based mud are in the field of interest these days (Gkay and Rex 1966).

In the last decade, so many investigations have been conducted on the effect of the herbal extract on the prevention of clay swelling. Some of these inhibitors showed that they had efficiency superior to other chemical inhibitors (Gkay and Rex 1966; Morton et al. 2005). Moslemizadeh et al. (2016) used a surfactant driven from Mulberry leaf as an Enhanced Oil Recovery (EOR) agent in montmorilloniterich reservoirs. The results of their experiments showed that this bio-based surfactant could strongly reduce clay swelling potential. Shadizadeh et al. (2015) evaluated the shale inhibition potential of natural surfactant derived from Zizyphus Spina-Christi extract (ZSCE). They showed that the (ZSCE) had a superior performance than $\mathrm{KCl}$.

Various coreflood tests by different researchers were conducted to verify the effect of clay hydration on formation damage. These researched give a good insight into the formation damage related to the clay swelling (Shadizadeh et al. 2015). Nevertheless, the flooding tests do not provide a porescale visualization (Barnaji et al. 2016). Therefore, the glass micromodel may help observe the pore-scale consequences of clay swelling on permeability reduction and formation damage. Sharifipour et al. (2017) performed an investigation on the impact of swelling clays on the oil exploitation process during low and high salinity water injection, by using a glass micromodel. The impact of metal nanoparticles on the hydration and migration of the clay mineral was studied by Sameni et al. (2015). The performance of the nanoparticles was assessed through different coreflood and glass micromodel tests. Coreflood test demonstrated that nanoparticles could not mitigate the swelling of clay minerals, and they increased the pressure drop during fluid injection due to pore plugging and bridging. However, they had a positive effect on the migration of clay particles.

As mentioned previously, coating the surface of the clay particles is one of the methods for preventing clay swelling. 
Surface-active agents or surfactants are a suitable option for this purpose. On the other hand, reduction and mitigation of clay swelling by bio-based inhibitors such as surfactants have been recently considered as a good option, which satisfies environmental issues concerns. One of the most commonly used materials for reducing clay swelling is potassium chloride $(\mathrm{KCl})$. The $\mathrm{K}^{+}$neutralizes the negative surface charge (ion exchange mechanism) of the clay particle and reduces its swelling. Despite its high efficiency, it may impose pollution on the environment. However, the presence of potassium ions may cause problems in the well logging. Natural potassium contains radioactive isotopes which emit gamma rays. Thus, potassium salts in the mud system may contribute to the gamma-ray tool response (Cox and Raymer 1977).

In this paper, we utilized a bio-based surfactant extracted from Acanthophyllum root to detract the formation damage caused by Mt swelling. The efficiency of the ACRE was compared to the $\mathrm{KCl}$ (Zhong et al. 2011; Rezaei and Shadizadeh 2021). To investigate the efficiency of this bio-based surfactant, firstly, some static tests, including sedimentation test, free swelling test, zeta potential test, Mt particle size measurement, and scanning electron microscopy (SEM), were applied to investigate the effect of the surfactant on montmorillonite. Finally, coreflood and micromodel tests were used to verify its impact on preventing of permeability reduction in the near-wellbore region.

\section{Materials and experimental approach}

\section{Materials}

\section{Surfactant}

Organic compounds, which contain both hydrophilic (head) and hydrophobic (tail) groups, are known as surface-active agents or surfactants. The nature of the hydrophilic group (head) makes the basis of their classification. (Kulikova et al. 2021) There are four main groups of surfactants, including cationic, anionic, non-ionic, and zwitterionic (Kumar and Mandal 2017; Rosen and Kunjappu 2012). Compared to the other three groups, non-ionic surfactants have various engrossing features such as low cost, compatibility, better biodegradation, and lower toxicity (Zhang 2020). Nonionic surfactants do not have a definite ionic charge. But the hydrophilic part bears polar functional groups like hydroxyl and ethylene oxide, which make it water-soluble (Xing et al. 2017). In recent years, different researchers have endeavored to develop and extract eco-friendly surfactant from natural resources (Akter et al. 2021; Pal et al. 2019). Acanthophyllum bracteatum, also called Chubak (Chooghan) by natives, is a member of the Caryophyllaceae family. There are 61 species of this genius in the world, 23 of which grow in Iran. Acanthophyllum bracteatum (Chubak) widely grows in Ghaenat, Khorasan province, Iran. A long time ago, natives used the crushed and milled roots, of this plant as detergents. There are diverse medical applications for this plant, and it also has an essential function as a desertification agent in arid areas (Jahanbin et al. 2011). The presence of saponin in the root of this plant gives its surfactant properties. Saponins are bio-surfactants chiefly generated by herbs and rarely by marine organisms and insects. More than 500 plant species contain this type of bio-surfactants (Güçlü-Üstündağ and Mazza 2007). Similar to synthetic non-ionic surfactants, Saponin molecules consist of both hydrophilic and hydrophobic part. The hydrophobic segment consists of steroid mainstay and triterpenoid; however, the hydrophilic section includes different sugar residues linked to the hydrophobic framework through glycoside bonds (Stanimirova et al. 2011).

\section{Expandable clay}

Bentonite was employed as a swelling smectite type clay in the tests. Methylene blue test (Tesema et al. 2020) results in a cation exchange capacity of $66.5 \mathrm{meq} / 100 \mathrm{gr}$ for this sample. The XRD analysis of the bentonite sample was provided by the supplier company. It was reported that the bentonite sample contains $61 \%$ of Mt, while feldspar (12.5\%), cristobalite $(11 \%)$, quartz $(8.5 \%)$, muscovite $(1.5 \%)$, anorthite $(1.5 \%)$, calcite $(1 \%)$, and Gypsum $(1 \%)$ are the other ingredients. As presented, montmorillonite is the most abundant hydratable component. So, swelling of the Bentonite sample is mainly related to the montmorillonite.

Potassium chloride $(\mathrm{KCl})$ and calcium chloride $\left(\mathrm{CaCl}_{2}\right)$ salts were purchased from Merck Company which we compared the effect of $A C R E$ with $\mathrm{KCl}$, the most common clay stabilizer.

\section{Experimental procedure}

\section{Surfactant extraction and solution preparation}

The spray dryer method (Ho et al. 2015) was applied to extract this bio-based surfactant from the roots of Acanthophyllum. The extracted powder is dark brown and has a special odor. The density of the powder equals $0.125 \mathrm{gr} /$ $\mathrm{cm}^{3}$, and it is easily dissolved in alcohol and water. After preparing ACRE powder, a certain amount of this powder was added to deionized water slowly and stirred with the magnet stirrer to obtain a master solution with a concentration of $6 \% \mathrm{Wt}$ (weight percentage). Then, the solutions with concentrations of $0.1,0.5,1,2,3,4,5$ by weight percentage were achieved through dilution of the master solution.

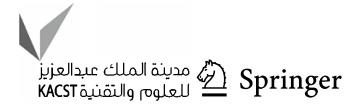




\section{Fourier transform infrared spectroscopy (FT-IR)}

In order to attribute the surfactant properties to saponin, the FT-IR test was conducted to demonstrate the existence of the saponin in the ACRE. Thermo Scientific FT-IR Spectrometer was utilized for recording FT-IR spectra. Potassium Bromide $(\mathrm{KBr})$ solid pellets were prepared by mixing $\mathrm{KBr}$ and solid samples. Infrared scanning was conducted between 400 and $4000 \mathrm{~cm}^{-1}$ at room temperature $\left(28^{\circ} \mathrm{C}\right)$.

\section{Critical micelle concentration (CMC) determination}

Molecules of the Surfactant are in the form of monomers when the concentration is low. Whenever the concentration increases and reaches the critical value (CMC), the formation of the micelles (aggregates) starts. At concentration above this value (CMC), the concentration of monomers remains constant while micelles concentration increases (Eslahati et al. 2020). One of the straightforward methods of CMC determination is to measure the electrical conductivity of the surfactant solution at different concentrations. In this research, Jenway Conductivity meter 4320 was used for electrical conductivity measurement. For this purpose, the following steps have been conducted: (1) Master solution of the surfactant was made by adding the surfactant powder to deionized water and stirring for 2 hours by a magnetic stirrer. (2) Preparation of different solutions by diluting the master solution with deionized water. (3) Measurement of conductivity of different solutions at room temperature. (4) Conductivity values were plotted against surfactant concentrations. (5) The amount of concentration at the inflection point refers to the CMC value.

In order to calculate the CMC of the ACRE solution with other methods, surface tension (ST) measurement was applied. (Mozaffari et al. 2017) The surface tensions between the surfactant solutions and air were measured at $75^{\circ} \mathrm{C}$ using the IFT4000 apparatus. This device conducts the tests based on the pendant drop approach. A drop of the surfactant solution (at various concentrations) was hung in the air environment, and the image of the droplet was captured by a precise camera. The picture was then transferred to the computer, and the ST is calculated by the software according to the following equation (Mehrabianfar et al. 2021).

$\gamma=\frac{\Delta \rho g D^{\prime 2}}{H}$

where $\Delta \rho$ represents density difference $\left(\mathrm{g} / \mathrm{cm}^{3}\right)$, $\mathrm{g}$ is the gravitational acceleration of the earth $\left(\mathrm{cm} / \mathrm{S}^{2}\right), D^{\prime}$ denotes the larger diameter of the droplet $(\mathrm{cm}), \mathrm{H}$ is a function of $\mathrm{S}=$ $d / D$, where $d$ stands for the smaller diameter at a distance $D$ from the top of the droplet.

\section{Swelling inhibition evaluation tests}

Sedimentation test Montmorillonite precipitates in an inhibitor-containing medium because it lowers swelling potential. In fact, it is in the form of flocculated particles (unstable) in the presence of an inhibitor and tends to precipitate due to its low ability to hydration and further swelling. After preparation of turbid dispersion of $5 \% \mathrm{Wt}$. montmorillonite in different concentrations of surfactant solution, montmorillonite settles as time passes. Therefore, after a particular period, a boundary appears between the supernatant phase and Mt sediment. Recording the ratio of $\mathrm{h}$ to $\mathrm{H}(\mathrm{h} / \mathrm{H})$ with respect to time gives a good signal of the inhibition potential of the medium (h: sediment height, $\mathrm{H}$ : dispersion total height) (Moslemizadeh et al. 2015; Api 1997).

Free swelling test The swelling index test is a common standard test (ASTM D5890-11) that is carried out to measure the inhibitive potential of the medium. Dry powder of Bentonite is placed into the graduated cylinder, and water is gently added to it; then, the increment in volume of clay is recorded. This test gives a fast and handy vision of the degree of inhibitive properties of the solution. The accuracy of this method is not high, but it is a good way to compare the inhibition degree of two or more solutions with each other. To perform this test, 5 grams of dry Mt is placed into a graduated cylinder, and $100 \mathrm{ml}$ of the different solutions of surfactant and deionized water is poured gently into the cylinder. Then, the cylinder is conserved from any disturbances for 24 hours. Finally, the increase in volume was recorded (Sameni et al. 2015).

$\operatorname{FSI}(\%)=\left(\frac{h_{f}-h_{0}}{h_{0}}\right) \times 100$

where FSI, Free Swelling Test, $h_{0}$ refers to the initial height of Mt powder in a neutral fluid like diesel oil, and $h_{f}$ demonstrates the final height of $\mathrm{Mt}$ in different solutions.

Zeta potential test The electro-kinetic property of $\mathrm{Mt}$ particles can be assessed by measurement of its zeta potential. Initially, Mt was added to deionized water to prepare Mt dispersion. The dispersions were kept static for 24 hours and then stirred at $600 \mathrm{rpm}$ for 20 minutes employing a magnet stirrer. ACRE solution with different concentrations of $0.1,0.15$, and 0.4 was blended with the Mt dispersion and then shaken for 24 hours at room temperature. Then, $5 \mathrm{ml}$ of different dispersions is required to put in the zeta sizer apparatus. Malvern UK 3600 Zetasizer was utilized to measure the zeta potential based on Henry's formula: 
$U_{E}=\frac{2 \varepsilon Z F\left(k_{a}\right)}{3 \mu}$

where $U_{E}$ is defined as the electrophoretic mobility; $\varepsilon$ shows the dielectric constant; $\mathrm{Z}$ is the zeta potential; $F\left(K_{a}\right)$ stands for Henry's function, and $\mu$ refers to viscosity (Darjani et al. 2021; Moslemizadeh et al. 2017).

Measurement of particle size Malvern UK 3600 Zetasizer was employed to measure the average particle size of $\mathrm{Mt}$ in dispersion. Measurements were conducted at room temperature $\left(28^{\circ} \mathrm{C}\right)$, and the particle size is reported in equivalent spherical diameter (nm). First, a dispersion of Mt was prepared by blending $0.1 \mathrm{gr}$ of $\mathrm{Mt}$ with deionized water. Then, a certain amount of ACRE was added and shaken for 24 hours to reach equilibrium. Finally, $5 \mathrm{ml}$ of the dispersion was put into the cell of the zeta sizer (Moslemizadeh et al. 2019).

Scanning electron microscopy (SEM) observation The morphological features like the texture of materials can be investigated by SEM analysis. (Ghasemi et al. 2021) So, the interaction between surfactant and Mt particles can be analyzed with two-dimensional pictures, which the SEM analysis output. Modified Mt powder with the different inhibitor solutions was selected for this test.

\section{Evaluation of surfactant on Mt swelling in porous media}

Coreflood test Preparation of porous medium Sand grains were collected and washed with different types of solvents like water, toluene, and methanol to ensure there was no impurity. The purified sand (quartz) grains were sieved, and the grains with the size of 90 to $130 \mu \mathrm{m}$ were picked as the main constituent of the porous medium. The porous medium was made up of $90 \% \mathrm{Wt}$ of quartz grain and $10 \% \mathrm{Wt}$ of Bentonite. Quartz grains and clay were mixed, and they were poured and packed into a one-inch stiff sleeve. A 74- $\mu \mathrm{m}$ size lace to prevent matrix movement covered the upper and lower part of the sleeve (Bazyari et al. 2018).

Implementation of flooding test When incompatible mud filtrate invades into clay-rich formation, clay may swell and cause permeability reduction in petroleum-bearing formations and near-wellbore region. In order to measure the amount of permeability reduction during the invasion of intruder fluid, coreflood tests were conducted. Figure 2 represents a schematic illustration of the apparatus. Before performing the test, the core was constrained under an overburden pressure of 2000 Psia employing a hydraulic jack. Then, the synthetic core was set under vacuum for 6 hours. At first, initial permeability was evaluated by injecting $\mathrm{CaCl}_{2}$ Solution $(10 \% \mathrm{Wt}$ or $100000 \mathrm{ppm})$ at three distinct small rates of $0.1,0.15$, and $0.2 \mathrm{ml} / \mathrm{min}$. The coreflood tests were conducted at low rates, because the high rates may cause turbulent flow in porous media, which may end in fine migration. After the initial permeability measurement, about four pore volumes of inhibitors solution were injected at three rates as mentioned above. The injected fluid was aged into the core sample for 12 hours. Finally, the initial $\mathrm{CaCl}_{2}$ solution $(10 \% \mathrm{Wt}$ or $100000 \mathrm{ppm})$ was injected to measure the permeability reduction. Secondary to primary permeability ratios lead to an index, which assists us in judging formation damage. (Zhang et al. 2019)

Darcy's equation for linear flow in the field unit is represented as follows (Mehrabianfar et al. 2020):

$q=1.127 \times 10^{-3} \frac{k A}{\mu} \frac{\Delta P}{L}$

where $\mathrm{q}$ is the flow rate (bbl/day), $\mathrm{k}$ is permeability $(\mathrm{mD})$, A is cross-sectional area $\left(\mathrm{ft}^{2}\right), \Delta P$ is pressure drop (psi), $\mu$ is fluid viscosity (cp), and $\mathrm{L}$ denotes length (ft).

The conversion factor changes from 1.127 to 0.004 if we put flow rate in $(\mathrm{ml} / \mathrm{min})$, cross-sectional area in $\left(\mathrm{cm}^{2}\right)$, and
Fig. 2 Coreflood experimental apparatus configuration

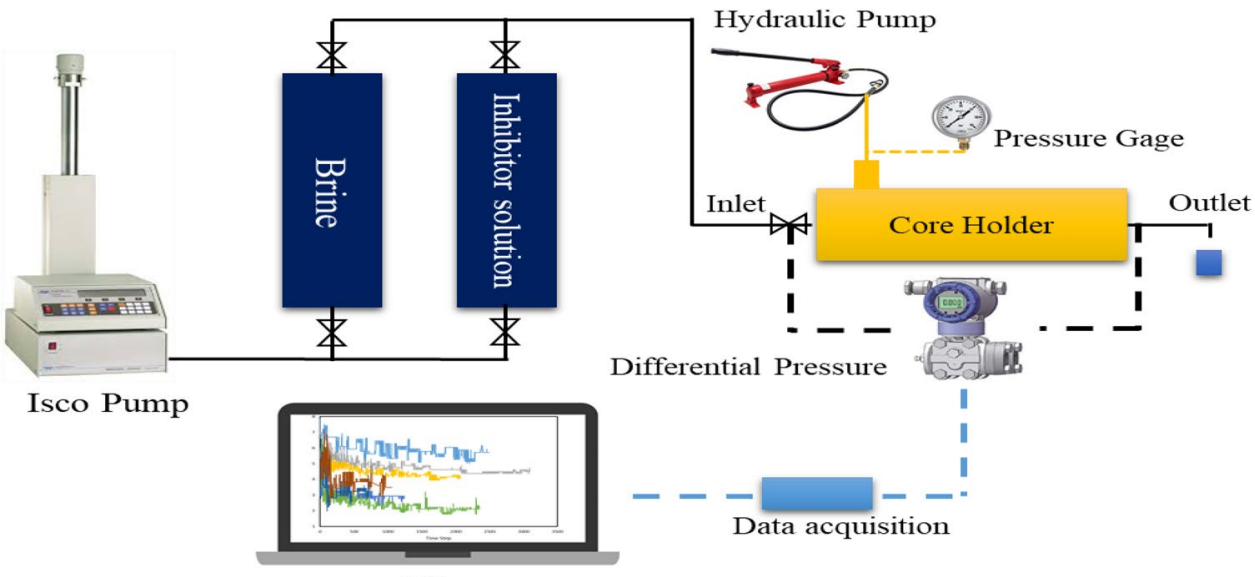

PC 
length in (cm). If q versus $\Delta P$ is plotted, permeability can be calculated from the slope $(\mathrm{m})$ of the line.

$k=m \mu l / 0.004 A$

In this test, the viscosity of $\mathrm{CaCl}_{2}$ solution approximately equals $1 \mathrm{cp}$, cross-sectional area equals $5.06 \mathrm{~cm}^{2}$, and core length varies through different tests.

Glass micromodel test Glass micromodel is a 2-D porous media sample, which has been widely used recently for visual investigation through the porous media. (Mozaffari et al. 2021) Different process mechanisms at the pore scale can be analyzed in this visual tool. As exhibited in Figure 3, the micromodel setup consists of a syringe pump with the capability of injection at too low rates, a high-quality Canon and Dino-Lite camera, a backlight source, and a computer system for recording the output of cameras. Corel Draw2018 software was utilized for designing a porous medium pattern. (Darjani et al. 2017; Bavarsad et al. 2020) The layout was engraved on a suitable glass with a powerful laser. After some manipulation (cleaning with acid), a glass with the same dimension was fused with the etched glass by placing it into a furnace. The synthetic visual micromodel with a porosity of $32.66 \%$ has a size of $12.6 \times 2.6 \mathrm{~cm}$, a pore volume of $0.527 \mathrm{ml}$, and a depth of $101 \mu \mathrm{m}$. The sizes of the pore and throats of this porous media are 2200 and $500 \mu \mathrm{m}$, respectively.

Pore plug tests were performed to measure the capability of Mt to swell and plug the throats in the presence of different solutions. For simulating a clay-containing medium, Mt dispersion in deionized water $(10 \% \mathrm{Wt}$.) was perfused through the micromodel. Then, the glass micromodel was dried by placing it into the furnace $\left(120^{\circ} \mathrm{C}\right)$. Then, four pore volumes of different solutions were injected into the micromodel. The injection rate was a constant value of $0.5 \mathrm{ml} / \mathrm{hr}$. After reaching to stable condition, a detectable and inert fluid (i.e., oil) was injected into the

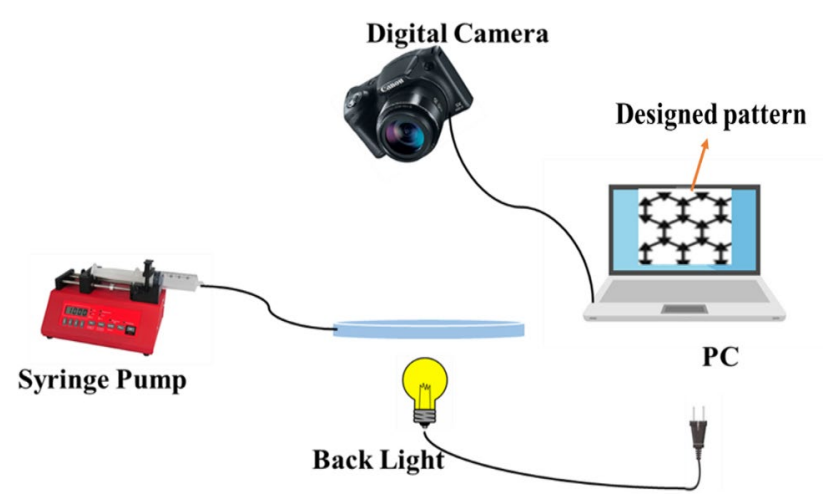

Fig. 3 Experimental setup of the micromodel micromodel to measure the blocking potential of $\mathrm{Mt}$ in the transparent porous media.

$P P I=\frac{V_{t}-V_{f}}{V_{t}} \times 100$

where PPI is pore plug index, $\%(0 \leq \mathrm{PPI} \leq 100) ; V_{t}$ is the total volume of a micromodel which can be filled by oil, Pixel; $V_{f}$ is the final oil volume in micromodel, Pixel (Moslemizadeh et al. 2016)

\section{Results and discussion}

\section{Critical micelle concentration (CMC) determination}

Aforementioned, one of the straightforward approaches for the determination of surfactants' CMC is to measure their conductivity versus concentration. Figure 4 presents the magnitude of conductivity plotted versus ACRE concentration. The magnitude of the electrical conductivity increases as the concentration of surfactant increases. However, as the surfactant concentration comes to a threshold point, a remarkable change in the slope of the curve is observed. It is because of the formation of micelle. The amount of concentration corresponding to the point of inflection refers to the $\mathrm{CMC}$ value, which equals $1.4 \% \mathrm{Wt}$. Figure 5 shows the different values of the surface tension (ST) corresponding to the different $A C R E$ concentrations. It is evident that utilizing this surfactant solution decreased the surface tension. Before reaching the CMC point, the ST had a higher reduction trend, while the $S T$ reduction rate decreased after the CMC due to the formation of micelles. The amount of CMC determined by this method equals $1.48 \% \mathrm{Wt}$, which is in acceptable agreement with the conductivity measurement method.

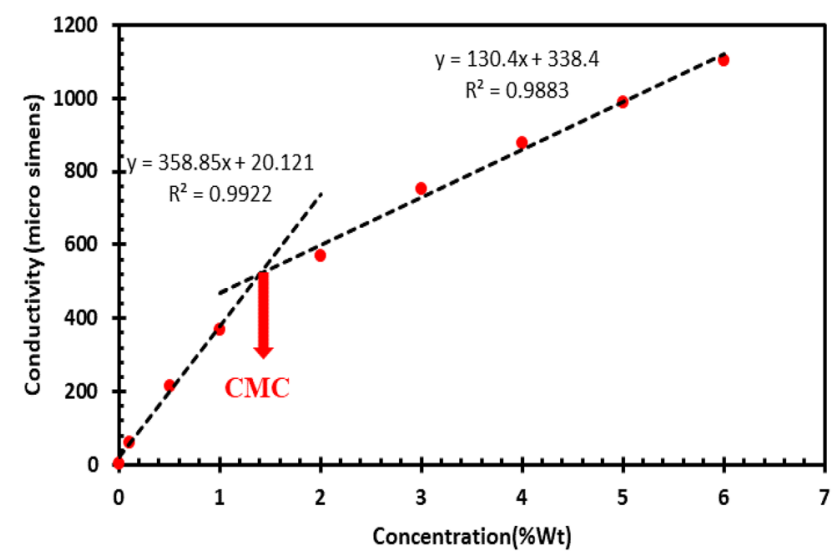

Fig. 4 Conductivity versus concentration plot for CMC determination of $A C R E$ 


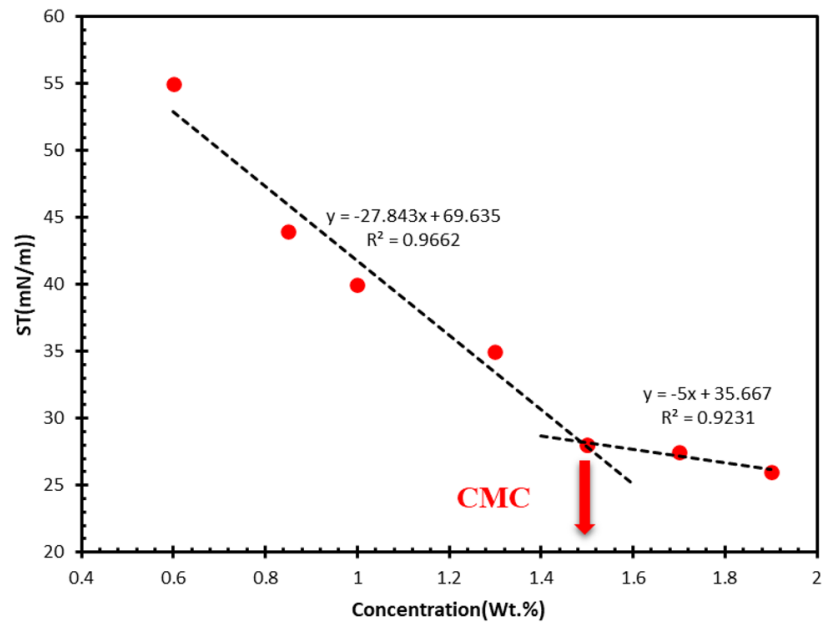

Fig. 5 Surface tension (ST) of the ACRE solution in different concentrations
Based on the presence of other components in ACRE, the CMC of the ACRE solution appears to be high compared to commercial chemical surfactants. Purification and separation of unwanted components of the $A C R E$ can yield a highquality natural surfactant. However, the CMC value falls into an acceptable range in comparison with other plant-based surfactants reported in the literature. For instance, Shadizadeh et al. evaluated the clay inhibition potential of Zizyphus Spina-Christi extract surfactant with CMC of $3.22 \% \mathrm{Wt}$ (Shadizadeh et al. 2015).

\section{FT-IR test result}

The spectral specifications of ACRE are presented in Fig. 6a. Fourier transform infrared spectroscopy (FT-IR) is a standard test for detecting the structure and functional groups of a substance. The surfactant exhibited the
Fig. 6 FT-IR spectrum of a $A C R E$ and corresponding functional group to their specific wave number $\mathbf{b}$ Comparison between the spectrum of ACRE and Glycyrrhiza Glabra extract (Khayati et al. 2020)
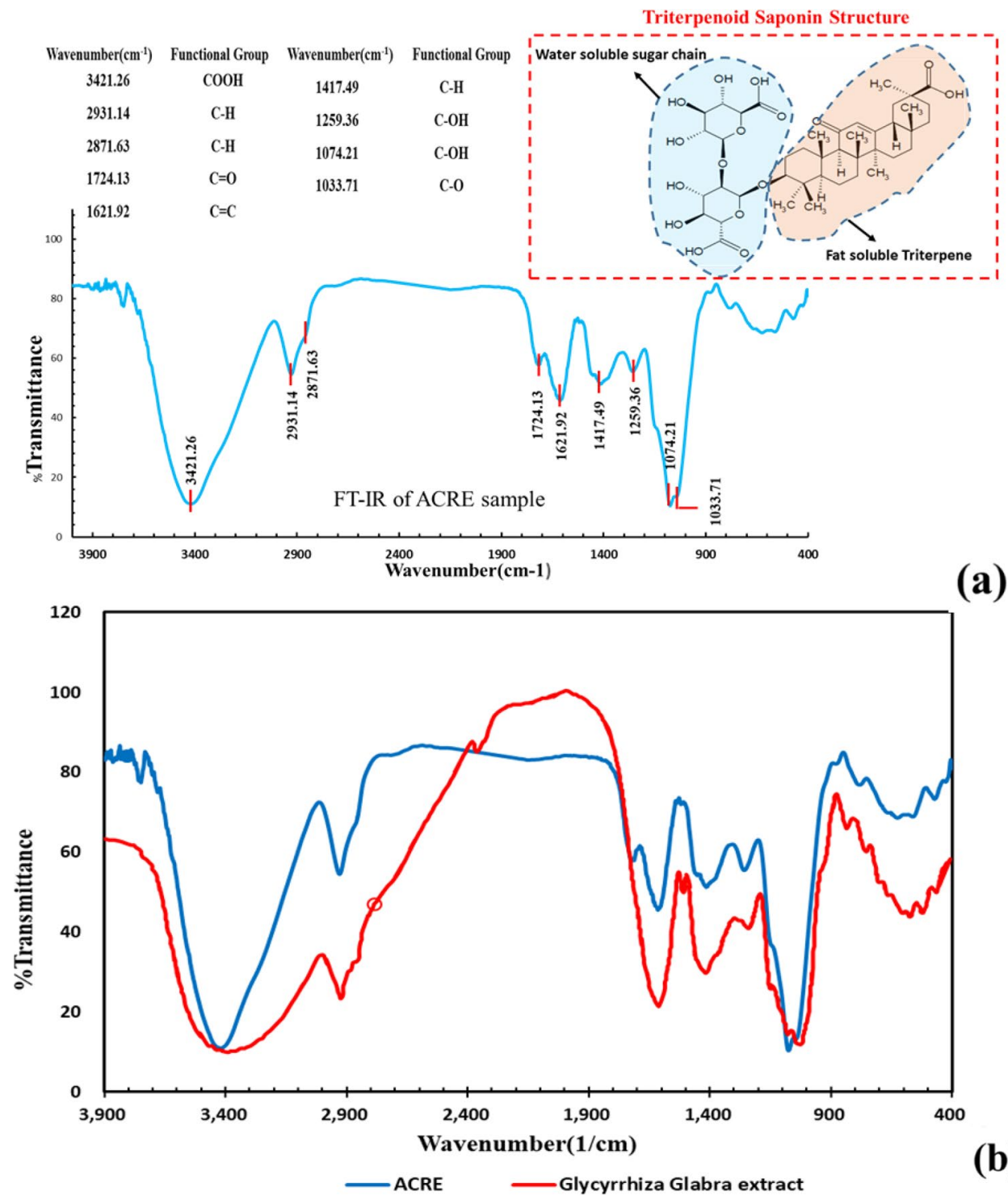

(a)

(b) 
characteristic spectrum of the hydroxyl group -OH attributed to the $3421.26 \mathrm{~cm}^{-1}$ peak, $-\mathrm{C}-\mathrm{H}$ stretching of alkane based on the peaks at $2931.14 \mathrm{~cm}^{-1}$, and $2871.63 \mathrm{~cm}^{-1}$, $\mathrm{C}=\mathrm{O}$ stretching detected from the peak at $1724.13 \mathrm{~cm}^{-1}$. These spectral features confirmed the presence of saponin and had a good harmony with the literature.

Acanthophyllum is a genus of plants that can be cultivated in arid and harsh areas which do not have specific plant life. In addition, it has a high content of saponin compared to other sources and high accessibility with lower cost. Based on the tests data, ACRE has a suitable inhibition performance and stability at high salinities and temperature. The mentioned characteristic is in considerable coincidence with what was previously studied in the spectrum of saponin, as shown in Fig. 6b. Therefore, it can be concluded that saponin also exists in ACRE (Khayati et al. 2020).

\section{Sedimentation test}

As mentioned earlier, montmorillonite is not stable in an inhibitive medium, and a stable dispersion cannot be formed. However, montmorillonite forms stable dispersion in deionized water. The results of the sedimentation test in the $\mathrm{pH}$ value of seven are exhibited in Fig. 7. Based on results, Mt forms a stable dispersion in deionized water and does not precipitate after 24 hours. These precipitations are because of the negative surface charges of Mt, which repel each other and form a stable dispersion. Therefore, Mt has a high swelling capacity in the presence of deionized water. On the other
Fig. 7 Mt sedimentation in a deionized water and different concentrations of $\mathrm{KCl} \mathbf{b}$ different concentrations of $A C R E$
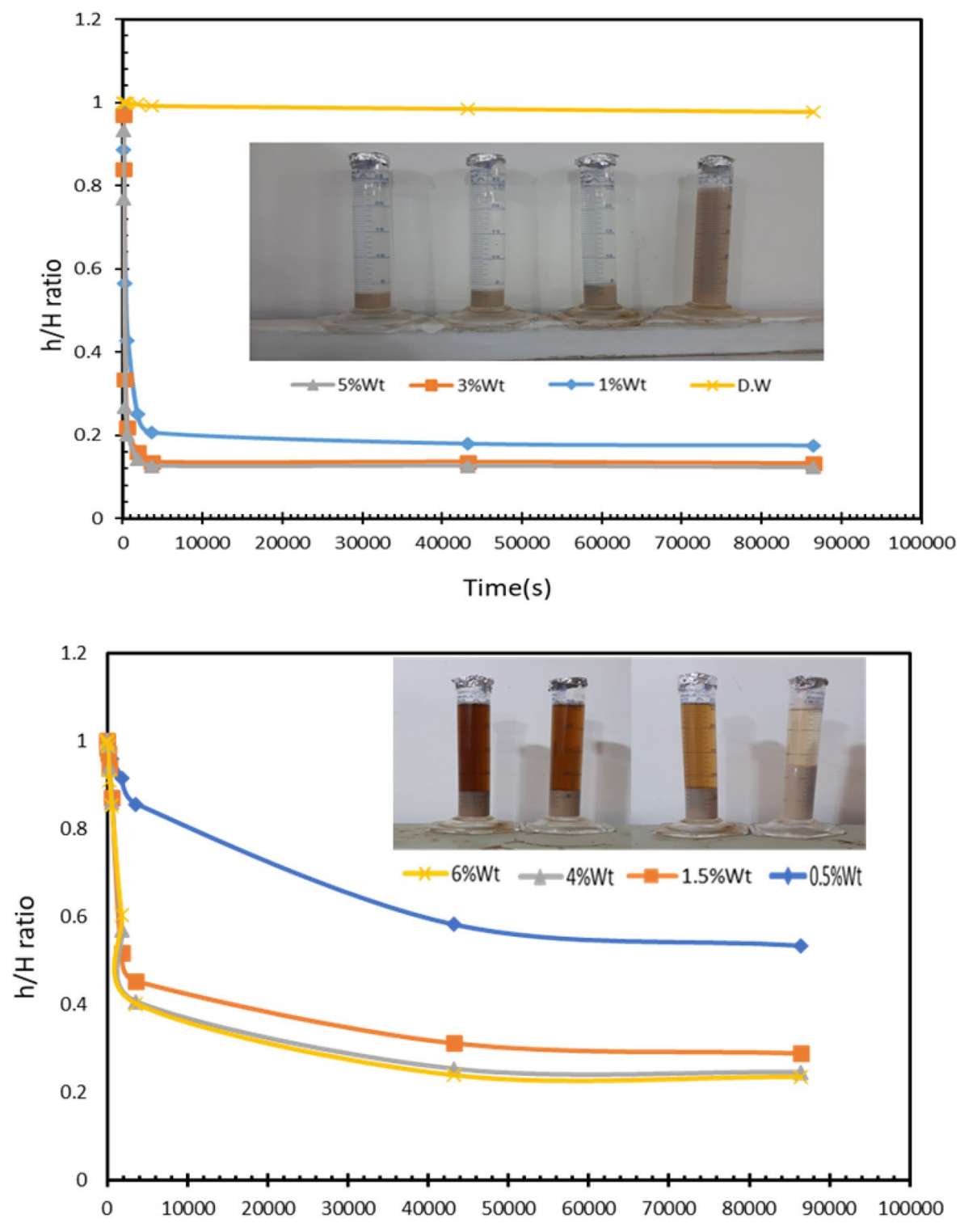

Time(s) 
hand, $\mathrm{KCl}$, as a widely used clay inhibitor, neutralizes the negative surface charge and makes the dispersion unstable. As presented in Fig. 7a, Mt particles begin to settle in a few minutes after that, dispersions come to a stationary condition. The initial boundary of the dispersion was observed at $60 \mathrm{~S}, 30 \mathrm{~S}, 10 \mathrm{~S}$ for $1 \%, 3 \%$, and $5 \%$ of $\mathrm{KCl}$ by weight percent, respectively. The more the concentration of $\mathrm{KCl}$, the lower the final sediment height. However, it is obvious that the final value of $(\mathrm{h} / \mathrm{H})$ for concentration of $3 \% \mathrm{Wt}$ and $5 \% \mathrm{Wt}$ is so close to each other. So, we used $4 \% \mathrm{Wt}$ of $\mathrm{KCl}$ as an optimum solution in proceeding tests. Figure $7 \mathrm{~b}$ shows that $A C R E$ molecules made the Mt dispersion unstable and made them settled. It confirms that $\mathrm{Mt}$ is not able to swell and hydrate in the presence of ACRE molecules. The magnitude of final $(\mathrm{h} / \mathrm{H})$ for $0.5,1.5,4$, and $6 \% A C R E$ by weight percentage reaches $0.53,0.29,0.24$, and 0.23 . The amount of sediment heights is inversely proportional to the concentration of $A C R E$, but the final value of $(\mathrm{h} / \mathrm{H})$ confirms that there is no remarkable improvement in the performance of the surfactant above CMC. Moslemizadeh et al. (2015) utilized Glycyrrhiza Glabra root extract (GGRE) as a swelling inhibitor. The results of the sedimentation tests revealed that the final value of $(\mathrm{h} / \mathrm{H})$ approximately reached 0.15 for a concentration of $8 \% \mathrm{Wt}$. However, it is clear that the efficiency of the ACRE is comparable with other bio-based inhibitors.

\section{Free swelling test}

When Mt exposes to water, polar molecules of water surround the crystal structure of $\mathrm{Mt}$ and result in a volume increase. Results of the free swelling index test in neutral $\mathrm{pH}$ are presented in Fig. 8. The amount of swelling of Mt exposed to deionized water reached 233.3 percent of its original volume, and other values were compared to this one. The ACRE solution made an obstacle for water molecules to contact with the surface of Mt molecules. Therefore, the amount of free swelling index has been reduced

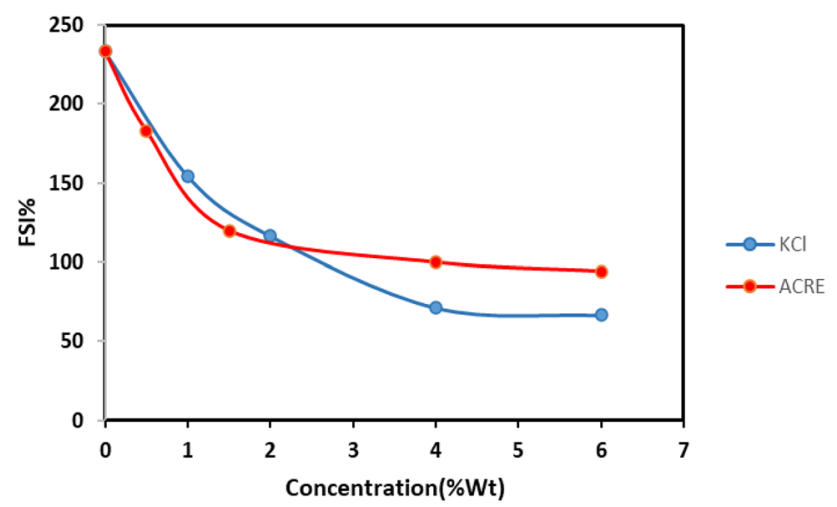

Fig. 8 Result of free swelling test in various concentrations of $A C R E$ and $\mathrm{KCl}$ solution sharply. Obviously, an increase in ACRE concentration reduced the amount of swelling, but at a concentration above the CMC, the amount of swelling difference was almost negligible. This may correspond to the fact that the concentration of the monomers is almost constant above CMC. To compare the performance of $A C R E$ with $\mathrm{KCl}$ (common clay inhibitor), $\mathrm{KCl}$ was used at four different concentrations $(1,2,4,6 \% \mathrm{Wt})$. It is evident from Fig. 6 that the performance of the ACRE solution was very close to the $\mathrm{KCl}$ solution at $\mathrm{CMC}$ concentration $(1.4 \% \mathrm{Wt})$. They both had an identical inhibition potential when the concentration increased to $2.1 \% \mathrm{Wt}$. However, $\mathrm{KCl}$ showed greater inhibition potential at higher concentrations, but the efficiency of the ACRE solution was still within an acceptable range.

Zargar et al. (2021) used an aluminum complex (AC) to prevent formation damage related to montmorillonite swelling. The amount of swelling index was diminished to $75 \%$ from an initial value of $185 \%$. So, the performance of the ACRE falls within an acceptable range compared to previous studies.

\section{Investigation on inhibition property of ACRE by zeta potential tests}

Zeta potential measurement is a simple and inexpensive method for evaluating the stability of Mt particles in the ACRE solution, because the interface charges of the $\mathrm{Mt}$ particles and ACRE solution can easily be detected. Considerable stability of water molecules around Mt particles and a great level of swelling are demonstrated by high negative zeta potential. (Moslemizadeh et al. 2017) From the test data in Fig. 9a, intact Mt in deionized water showed a high negative zeta potential value $(-18.7 \mathrm{mv})$ because of isomorphous substitution in its octahedral and tetrahedral sheets. A high negative zeta potential value indicates that a thick water layer has surrounded the Mt particles and, consequently, the high potential of Mt swelling. However, the addition of ACRE to the solution reduced the magnitude of zeta potential (Shifting toward positive). This reduction in zeta potential probably can be attributed to the coating of Mt by ACRE and, consequently, the inability of water molecules to form a stable film around Mt. Furthermore, based on the test data represented in Fig. 9a and zeta potential ranges in the literature (Riddick 1968), the addition of $A C R E$ to the Mt dispersion reduced the stability of the dispersion. Therefore, as the zeta potential magnitude moves toward zero, Mt particles delamination is hindered and the particles are maintained in a flocculated state. In this way, another justification of the Mt particles settlement in the sedimentation test can be established. 
Fig. 9 a Mean zeta potential b Average size of Mt particles in various concentrations of $A C R E$ solution
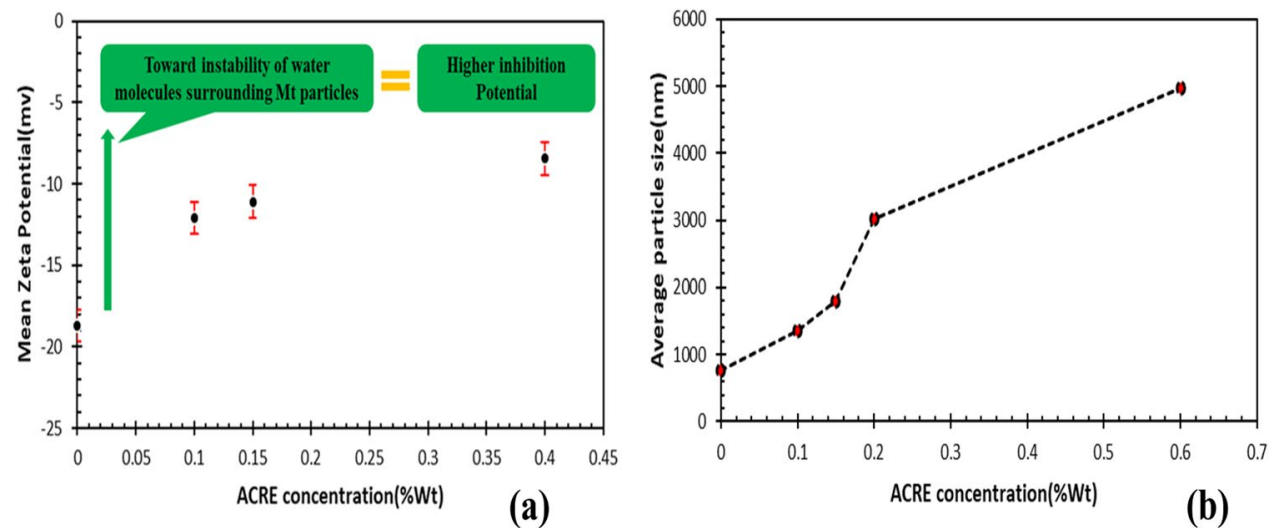

\section{Montmorillonite particle size}

When Mt particles contact with non-inhibitive solution, especially deionized water, they swell and delaminate. Delamination of Mt particles leads to increasing particles number and consequently reducing particle size (growth in specific surface area). Therefore, measuring of the Mt particle size in various aqueous solutions may assist us in judging the inhibitive features of the different solution (Au and Leong 2013). The delamination rate is proportional to the inhibitive potential of the solution. So, high delamination exhibits the low inhibitive potential of the solution. Based on Fig. 9b, when Mt was exposed to deionized water, it adsorbed water and became dissociated. Hence, it had the smallest size $(755.9 \mathrm{~nm})$. On the other hand, Mt particles had a larger average particle size in the presence of ACRE solution. Saponin molecules rest on the Mt surface and hinder water molecules from interacting with Mt. For example, the corresponding average particle size to the concentration of $0.6 \% \mathrm{Wt}$. is $4966.1(\mathrm{~nm})$. Therefore, the ACRE solution can effectively preserve Mt particles from delamination.

\section{SEM observations}

The performance of the surfactant in the impediment of montmorillonite swelling was also analyzed using SEM. Modified Mt powder was utilized to perform SEM analysis. Based on the figures, Mt powder has a small size in the presence of deionized water, which is related to swelling and, consequently, delamination of Mt particles. The small size and dense texture of $\mathrm{Mt}$ in deionized water are shown in Fig. 10a. On the other hand, Mt particles have a larger size and open texture in an inhibitive medium, which offers the stability of the particles. Figure $10 \mathrm{~b}$ and c displays the larger size of aggregates in inhibitive solutions of $A C R E$ and $\mathrm{KCl}$, respectively.

\section{Thermogravimetric analysis (TGA)}

In this research, a thermogravimetric analysis test was performed with Q600_TA to assess the stability of the ACRE at high temperatures. The experiment was carried out using $2.252 \mathrm{mg}$ of ACRE sample at temperatures ranging from 25 to $300{ }^{\circ} \mathrm{C}$. The temperature was raised by $10{ }^{\circ} \mathrm{C}$ per minute by an inert gas, i.e., Argon (Ar). Based on the results shown in Fig. 11, the red curve of the graph is related to the derivative of the weight percent versus temperature (the red curve is the derivative of the black curve). According to these two curves, it can be observed that weight loss consists of three main parts. The first section commenced at $95.2^{\circ} \mathrm{C}$ and ended at $141.5^{\circ} \mathrm{C}$. The weight reduction in the first part can be attributed to the moisture and surface water evaporation of the surfactant (Chigwada et al. 2006). The surfactant weight loss in the temperature range of $141.5-241.5^{\circ} \mathrm{C}$ can be related to the evaporation of the intermolecular water (Nikoobakht and El-Sayed 2001). At elevated temperatures (higher than $241.5^{\circ} \mathrm{C}$ ), the carbon bonds start to break down and vanish (Maria et al. 2002). Based on the results shown in Fig. 11 and the typical range of reservoirs temperature, increasing the temperature to $100{ }^{\circ} \mathrm{C}$ resulted in only a 1.98 percent weight reduction. This weight reduction can be attributed to the moisture and surface water evaporation of the surfactant. Therefore, the ACRE surfactant is adequate for application in the reservoir due to its suitable thermal stability.

\section{Compatibility test}

This test was conducted to determine critical salinity and evaluate the compatibility of the ACRE solution. To perform this test, $5 \mathrm{ml}$ of the ACRE solution at CMC and $5 \mathrm{ml}$ of various $\mathrm{NaCl}$ solutions were stirred and poured into the test tube. The test tubes were stored at $25^{\circ} \mathrm{C}$ for two weeks. Eventually, the sediments from each test tube were collected using filter paper, dried in the oven for one day, and weighted. Figure 12 

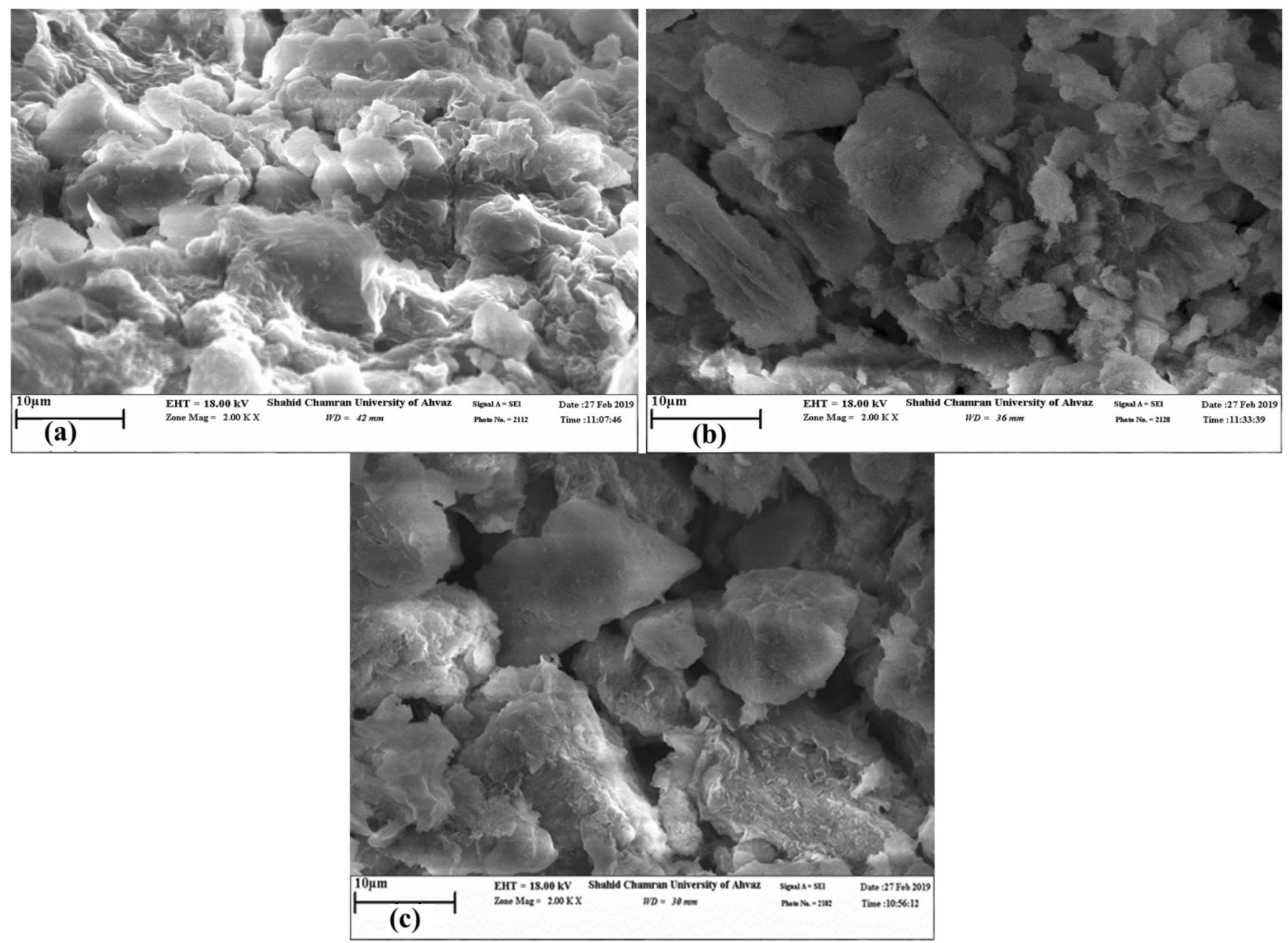

Fig. 10 SEM photograph of Mt powder modified by $\mathbf{a}$ deionized water $\mathbf{b} A C R E$ solution $\mathbf{c} \mathrm{KCl}$ solution

Fig. 11 TGA analysis conducted on ACRE and the corresponding weight loss due to temperature rise

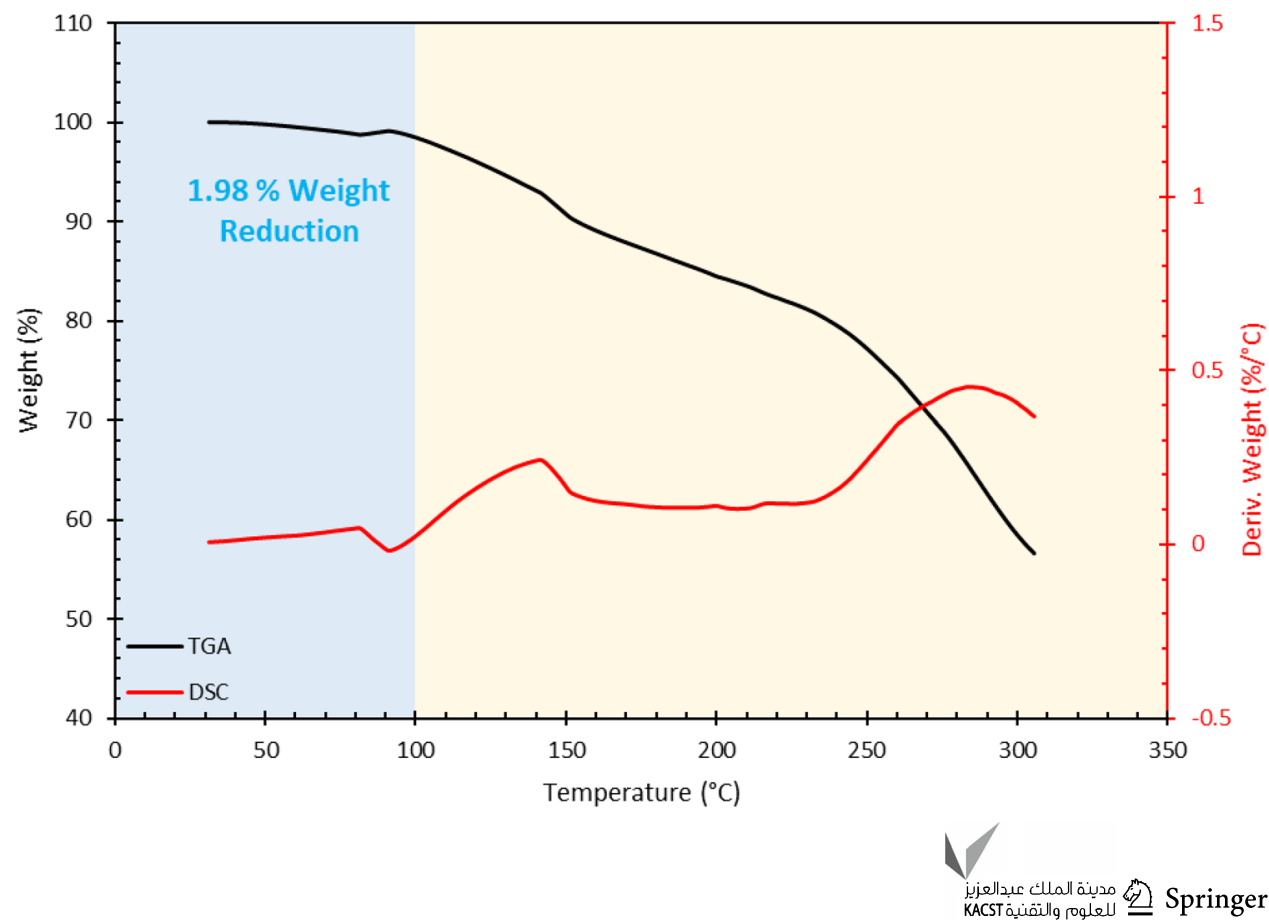


Fig. 12 Compatibility of ACRE solution at $\mathrm{CMC}$ in the presence of $\mathrm{NaCl}$ solutions

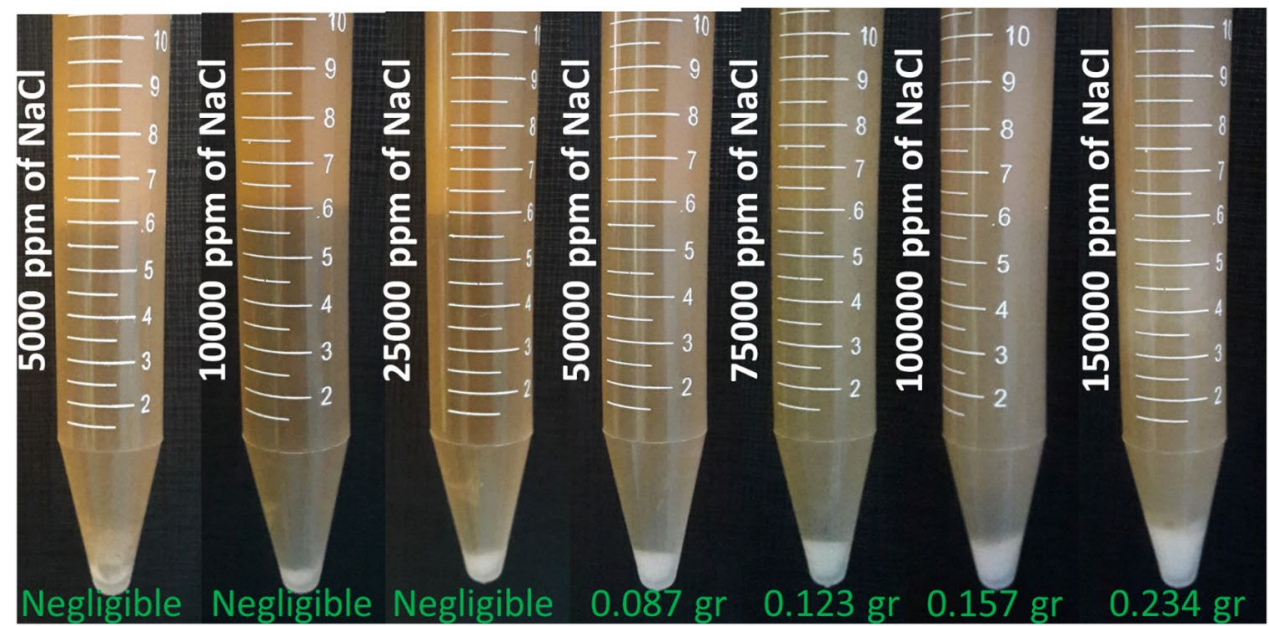

shows the result of the $A C R E$ solution compatibility test with different salinities of $\mathrm{NaCl}$ solutions. The amount of sediment is negligible for salinities of 5000, 10000, and 25000 $\mathrm{ppm}$. The amount of precipitation is $0.087,0.123,0.157$, and $0.234 \mathrm{gr}$ for $\mathrm{NaCl}$ solutions with concentrations of 50000 , 75000,100000 , and 150000 ppm, respectively. The compatibility test was conducted at room temperature and showed negligible sediment below the salinity of $50000 \mathrm{ppm}$. However, it is well known that increasing temperature improves solubility. Therefore, at higher temperatures like reservoir temperature, the sediments precipitate at salinities greater than 50000 ppm.

Nowrouzi et al. (2020) assessed the compatibility of a renewable surfactant extracted from the waste chicken fat at different $\mathrm{NaCl}$ salinity conditions. There was not any sediment for the salinities of 20000, 30000, 50000, 70000, and $100000 \mathrm{ppm}$, and the solutions remained stable. However, 0.1417 and $0.2376 \mathrm{~g}$ of sediment were observed at salinities of 130000 and 160000 ppm, respectively. Therefore, the compatibility of the ACRE solution at various $\mathrm{NaCl}$ salinities is satisfying compared to the former studies.

\section{Results of the efficiency of ACRE on prevention of Mt swelling in porous media}

\section{Results of coreflood test}

In this section, the $A C R E$ solution's performance in reducing of Mt swelling and pore blocking was evaluated through a series of coreflood tests. Figure 13a represents the plot of flow rate $(\mathrm{q})$ versus pressure drop $(\Delta P)$. Three different flow rates $(0.1,0.15,0.2 \mathrm{ml} / \mathrm{min})$ and corresponding pressure drop were recorded and plotted for five distinct tests. Based on the slope of the line and equation 5, primary permeabilities (prior to injection of inhibitors solution) were calculated.
The primary permeabilities for five different samples range from $82.7(\mathrm{mD})$ to $103(\mathrm{mD})$.

$A C R E$ solution at three different concentrations of $1,1.5$, and $4 \%$ by weight percentage was injected into the core sample through test numbers one to three, respectively. Based on Fig. 13 b and Table 1 , the final permeability reduced 0.57 , 0.61 , and 0.72 of its original value for the test one to three, respectively. In the fourth test, $4 \% \mathrm{KCl}$ by weight percentage was injected into the core, and the ultimate permeability reached to 0.81 of the primary value. As we expected, the most reduction in permeability occurred while deionized water was injected into the synthetic core. Most of the pores and throats of the porous medium were blocked due to the Mt swelling, and consequently, the pressure drops during the injection process raised sharply. The final permeability reduced to 0.11 of its initial value, and this means that almost 90 percent of the fluid flowing pass was blocked or restricted. According to the results of the coreflood test, when ACRE solutions were used as Mt inhibitor, the permeability reduction was mitigated. This reduction can be attributed to the saponin molecules, which reduced the interaction of Mt surface and water molecules by making a hydrophobic shield around Mt particles.

\section{Results of micromodel tests}

In this test, four pore volume of deionized water was injected through the micromodel. As mentioned earlier, Mt particles have high swelling potential in the non-inhibitive medium; therefore, they swell and plug pores in the porous medium. Figure 14a exhibits the plugging of pores in micromodel after water injection. The inert phase (oil) could just enter into a single path, and most of the zones are plugged, so the volume of entered oil into the micromodel is minimal. As a reference case, $4 \% \mathrm{Wt}$ of the $\mathrm{KCl}$ solution was injected into the micromodel. Based on the previous tests, Mt has the lowest tendency to swell in the presence of $\mathrm{KCl}$ solution. 
Fig. 13 Flow rates versus pressure drop during measurement of $\mathbf{a}$ initial permeability $\mathbf{b}$ final permeability
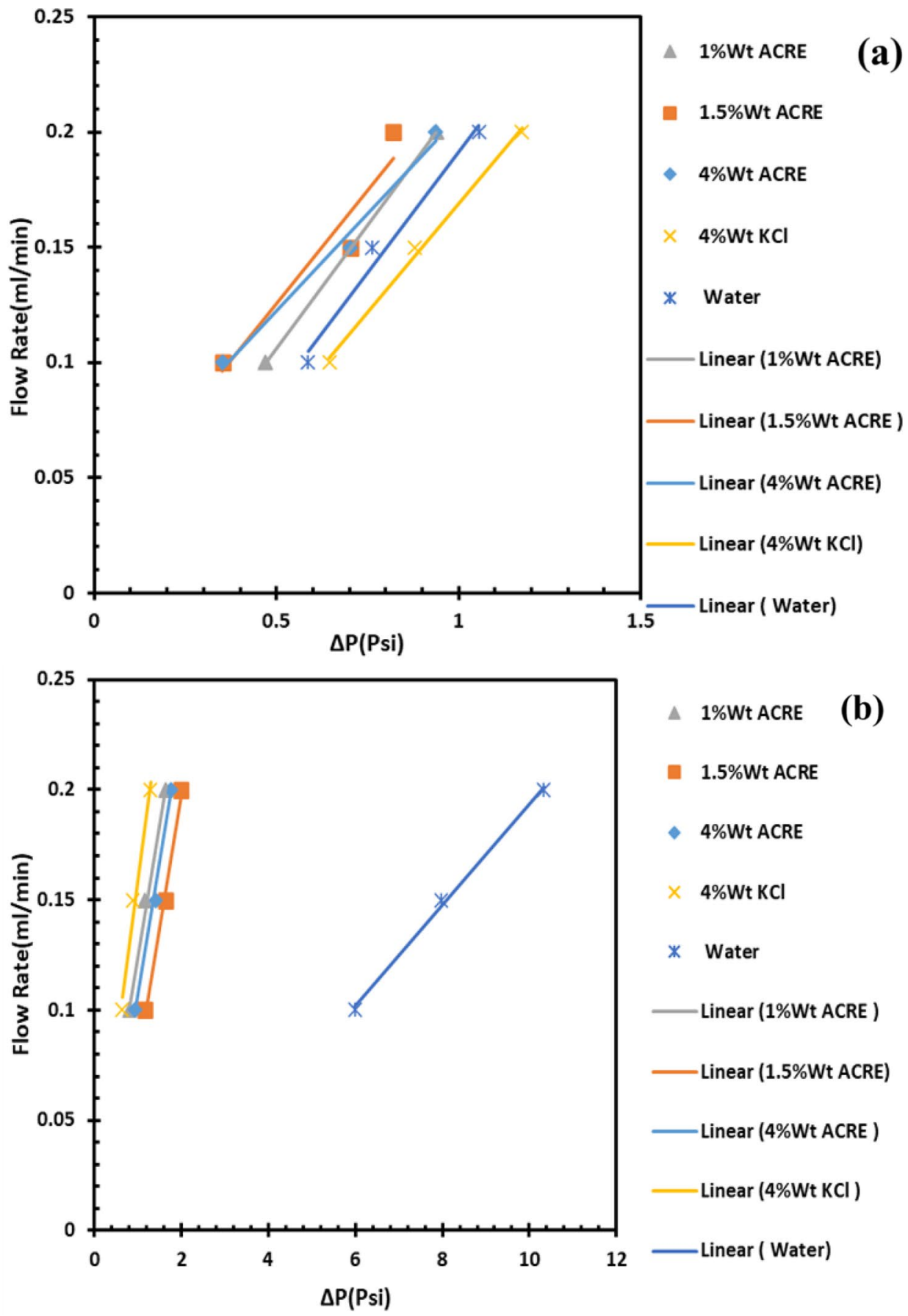

Potassium ions neutralized negative surface charges of $\mathrm{Mt}$ surface and suppressed the swelling process. The micromodel test result also proved this fact. Based on Fig. 14b, the maximum amount of oil has been entered into the porous medium compared to test number one. This means that most of the pores are still open and can serve as a fluid flowing path. After injection of four pore volumes of $1.5 \%$ ACRE by weight percentage solution through the micromodel, oil was injected to peruse the impact of ACRE solution on swelling mitigation. Based on Fig. 14c, much more oil has been entered into the medium, which demonstrates the efficiency of this bio-surfactant in the prevention of swelling and plugging of Mt. By comparing this test and the earlier tests, it is inferred that the efficiency of $A C R E$ solution is comparable to $\mathrm{KCl}$ solution.

After exposing Mt to different solutions, oil was injected into the micromodel to quantify the swelling and plugging of pores. By recording the pump volume and pixel analysis, the pore plug index (PPI) is calculated according to Eq. 6 . The amount of PPI after injection of deionized water is the 
Table 1 Summary of the coreflood test results

\begin{tabular}{|c|c|c|c|c|c|c|}
\hline Solution & Status & Trend line & Error $\left(R^{2}\right)$ & $\mathrm{Q} / \Delta P(\mathrm{ml} / \mathrm{min} . \mathrm{psi})$ & $\begin{array}{l}\text { Permeabil- } \\
\text { ity }(\mathrm{mD})\end{array}$ & PR (\%) \\
\hline \multirow[t]{2}{*}{$1 \%$ ACRE } & Initial & $y=0.213 X$ & & 10.213 & 103 & \multirow[t]{2}{*}{0.57} \\
\hline & Final & $\mathrm{y}=0.1209 X+0.0034$ & $R^{2}=0.9$ & 30.1209 & 59.1 & \\
\hline \multirow[t]{2}{*}{ 1.5\%ACRE } & Initial & $y=0.1968 X+0.0269$ & $R^{2}=0.92$ & 80.1968 & 99.6 & \multirow[t]{2}{*}{0.61} \\
\hline & Final & $\mathrm{y}=0.1209 X-0.0439$ & $R^{2}=0.99$ & 20.1209 & 61.2 & \\
\hline \multirow[t]{2}{*}{ 4\%ACRE } & Initial & $\mathrm{y}=0.1684 X-0.0381$ & $R^{2}=0.98$ & 70.1684 & 82.7 & \multirow[t]{2}{*}{0.72} \\
\hline & Final & $\mathrm{y}=0.121 \mathrm{X}-.0156$ & $R^{2}=0.9$ & 30.121 & 59.5 & \\
\hline \multirow[t]{2}{*}{$4 \% \mathrm{KCl}$} & Initial & $y=0.1886 X-.0197$ & $R^{2}=0.99$ & 90.1886 & 96.3 & \multirow[t]{2}{*}{0.81} \\
\hline & Final & $\mathrm{y}=0.1512 X-.0081$ & $R^{2}=0.97$ & 80.1512 & 77.8 & \\
\hline \multirow[t]{2}{*}{ D.W } & Initial & $y=0.2087 X-0.0173$ & $R^{2}=0.97$ & 60.2087 & 101.7 & \multirow[t]{2}{*}{0.11} \\
\hline & Final & $\mathrm{y}=0.023 X-0.0361$ & $R^{2}=0.99$ & 80.023 & 11.2 & \\
\hline
\end{tabular}

Fig. 14 Photos of pore plugging test after a deionized water, $\mathbf{b}$ $4 \% \mathrm{Wt}$ of $\mathrm{KCl}$ solution, and $\mathbf{c}$ $1.5 \% \mathrm{Wt}$ ACRE solution injection into micromodel
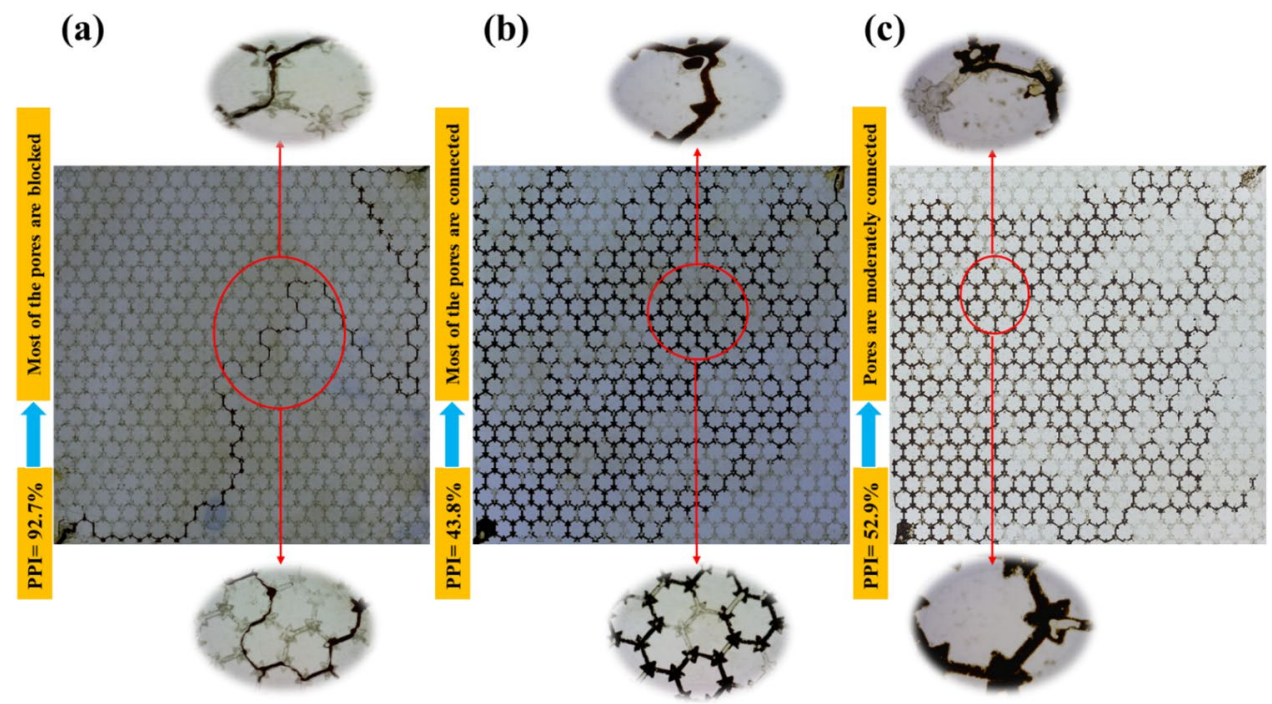

maximum value, which means that most pores were plugged after exposure to water and the oil saturation is the lowest value. However, injection of the bio-based surfactant solution reduced the PPI value due to the prevention of $\mathrm{Mt}$ swelling, and the result is approximately similar to $\mathrm{KCl}$. By comparing the results of coreflood and micromodel tests, it is evident that exposure of $\mathrm{Mt}$ particles to deionized water in porous media leads to plugging and blocking almost 90 percent of flowing routes. On the other hand, the application of the ACRE solution demonstrated that the permeability reduction and pore blocking were mitigated to nearly 60 percent.

\section{Probable inhibition mechanism by surfactant}

Plant-based clay inhibitors do not have a distinct chemical formula compared to chemical stabilizers. Therefore, the determination of a conclusive inhibition mechanism is a complicated matter. $A C R E$ is composed of various constituents, including minerals and organic compounds. Saponin, a non-ionic surfactant, is a prominent swelling stabilizer among other ACRE ingredients. Because of isomorphous substitution in octahedral and barely in tetrahedral sheets, Mt particles contain a negative surface charge. Saponins comprise hydrophobic and hydrophilic parts. When Mt particles are exposed to the $A C R E$ aqueous solution, the hydrophilic segment is absorbed into the negative surface charge of Mt by hydrogen bonding. (The hydroxyl group of the hydrophilic part is bonded to the negatively charged oxygen atoms on $\mathrm{Mt}$ ). By adsorption of Saponin molecules on the Mt surface, the hydrophobic part of saponin is oriented outward and forms a hydrophobic protective shield on the surface of Mt. This shield impedes the interaction between water molecules and $\mathrm{Mt}$ surface and consequently mitigates swelling. Schematic illustrations of Mt swelling and the probable treatment process are exhibited in Fig. 15. 


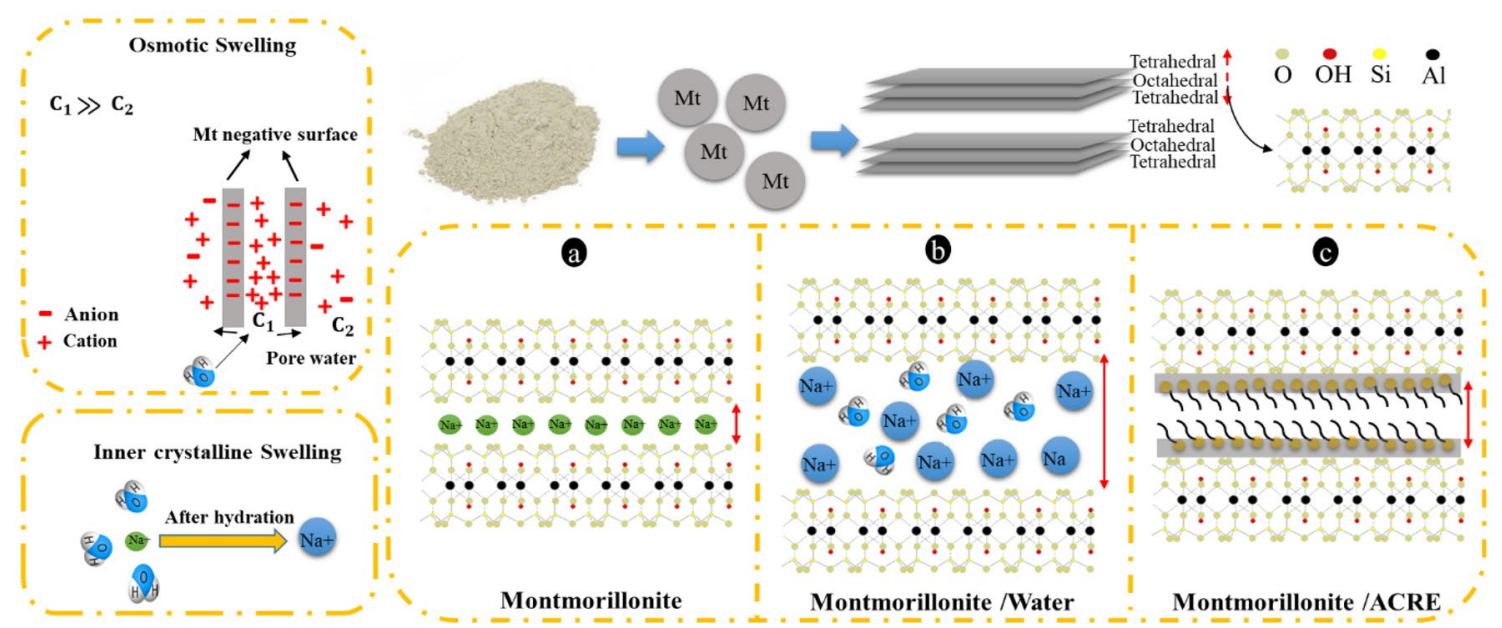

Fig. 15 Montmorillonite structure a primary state $\mathbf{b}$ exposed to water $\mathbf{c}$ in the presence of $A C R E$ solution

\section{Environmental and expenditure benefits}

During drilling, various chemical additives are applied to drilling mud, some of which are toxic and can strongly affect the environment. Clay inhibitors may cause contamination to drilling mud based on their chemical composition. $\mathrm{KCl}$ is one of these materials that is commonly used to inhibit clay swelling, but it has a negative impact on the soil and surface waters. Therefore, the substitution of a chemical additive with a biodegradable one is a suitable option. Grinded Acanthophyllum root was traditionally utilized as detergent by some natives in Iran. Another important benefit of this plant is that it can be widely cultivated as a desertification agent. The extract derived from the roots is a bio-surfactant that does not have a critical impact on the environment. Hence, it can be degraded in the environment without a severe threat.

It is well known that the reduction of expense in each stage of petroleum exploitation, especially drilling and production operation, improves the efficiency of the process. Considering the economic perspective, Acanthophyllum is a plant that is easily found in the Middle East, especially in Iran, at a low cost (US\$ 1-2 per Kilogram of roots on a laboratory scale) in comparison with other chemicals, particularly $\mathrm{KCl}$. ACRE has an extensive application in traditional medicine, and the application can be extended in other industries and petroleum engineering.

\section{Conclusion}

This research made a thorough investigation of the efficiency of a bio-based surfactant called Acanthophyllum root extract for Mt swelling prevention. The sedimentation test revealed that ACRE molecules made the Mt particles unstable and caused their settlement. Zeta potential tests proved that employing this bio-based surfactant in an aqueous solution containing Mt particles moves the zeta potential value toward zero. Therefore, water molecules are not able to form a stable film around Mt and the Mt particles become unstable and deposits (as observed in sedimentation tests). Reduction in the Mt negative surface charge confirms that Mt cannot swell and hydrate in the presence of ACRE molecules. Free swelling tests elucidated that the ACRE aqueous solution reduced the FSI to 94.4 from 233.3\%. Particle size measurement and SEM analysis revealed that Mt has a small size in the presence of deionized water, which is related to swelling and, consequently, delamination of Mt particles. On the other hand, Mt particles have a larger size and open texture in the surfactant solution, which shows the integrated structural sheets of Mt. All the previous static tests confirmed that the ACRE solution has an acceptable inhibition property. ACRE solution compatibility test at $25^{\circ} \mathrm{C}$ demonstrated negligible precipitation for salinities less than $50000 \mathrm{ppm}$ of $\mathrm{NaCl}$ at $\mathrm{CMC}$ of surfactant. Thus, injection of the ACRE solution at reservoir conditions will not cause scale deposition. Eventually, the efficiency of this bio-surfactant is verified in porous mediums using coreflood and micromodel tests. The results demonstrate that the $A C R E$ solution can prevent permeability impairment and pore plugging.

With respect to the results, it is evident that the ACRE solutions do not have impressive effectiveness at higher concentrations than CMC. It can be inferred that monomers play a leading role in Mt swelling reduction than micelles. Therefore, the optimum concentration should be close to $\mathrm{CMC}(=1.4 \% \mathrm{Wt})$ to lead to a favorable result. 


\section{Recommendations}

According to this study, this surfactant can be used in various fields of petroleum engineering. But the advice for other researchers is to continue these tests at higher temperatures. Also, measuring the temperature stability over time can be good option.

\section{Declarations}

Conflict of interests The authors declare that they have no known competing financial interests or personal relationships that could have appeared to influence the work reported in this paper.

Open Access This article is licensed under a Creative Commons Attribution 4.0 International License, which permits use, sharing, adaptation, distribution and reproduction in any medium or format, as long as you give appropriate credit to the original author(s) and the source, provide a link to the Creative Commons licence, and indicate if changes were made. The images or other third party material in this article are included in the article's Creative Commons licence, unless indicated otherwise in a credit line to the material. If material is not included in the article's Creative Commons licence and your intended use is not permitted by statutory regulation or exceeds the permitted use, you will need to obtain permission directly from the copyright holder. To view a copy of this licence, visit http://creativecommons.org/licenses/by/4.0/.

\section{Reference}

Akter N, Mawardi Ayob MT, Radiman S, Khandaker MU, Osman H, Alamri S (2021) Bio-surfactant assisted aqueous exfoliation of high-quality few-layered graphene. Crystals 11(8):944

Api R (1997) B-1 Recommended practice standard procedure for field testing water-based drilling fluids. Americal Petroleum Institute Publishing Services, USA

Au P-I, Leong Y-K (2013) Rheological and zeta potential behaviour of kaolin and bentonite composite slurries. Colloids Surf A Physicochem Eng Asp 436:530-541

Barnaji MJ, Pourafshary P, Rasaie MR (2016) Visual investigation of the effects of clay minerals on enhancement of oil recovery by low salinity water flooding. Fuel 184:826-835

Bavarsad AS, Mehrabianfar P, Malmir P (2020) Investigation of performed particle gels on improvement of water eor performance; using glass micromodel and UTCHEM simulator. In: 82nd EAGE annual conference \& exhibition, 2020, vol. 2020, no. 1, pp. 1-5: European Association of Geoscientists \& Engineers

Bazyari A, Soulgani BS, Jamialahmadi M, Dehghan Monfared A, Zeinijahromi A (2018) Performance of smart water in clay-rich sandstones: experimental and theoretical analysis. Energy Fuels 32(10): 10354-10366

Chigwada G, Wang D, Wilkie CA (2006) Polystyrene nanocomposites based on quinolinium and pyridinium surfactants. Polym Degrad Stab 91(4):848-855

Darjani S, Koplik J, Pauchard V (2017) Extracting the equation of state of lattice gases from random sequential adsorption simulations by means of the Gibbs adsorption isotherm. Phys Rev E 96(5):052803

Darjani S, Koplik J, Pauchard V, Banerjee S (2021) Adsorption kinetics and thermodynamic properties of a binary mixture of hard-core particles on a square lattice. J Chem Phys 154(7):074705
Eslahati M, Mehrabianfar P, Isari AA, Bahraminejad H, Manshad AK, Keshavarz A (2020) Experimental investigation of Alfalfa natural surfactant and synergistic effects of $\mathrm{Ca} 2+, \mathrm{Mg} 2+$, and $\mathrm{SO} 42-$ ions for EOR applications: interfacial tension optimization, wettability alteration and imbibition studies. J Mol Liq 310:113123

Cox JW, L. Raymer L (1977) The effect of potassium-salt muds on gamma ray, and spontaneous potential measurements. In: SPE California Regional Meeting, 1977: OnePetro

Amaefule JO, Kersey DG, Norman DK, Shannon PM (1688) Advances in formation damage assessment and control strategies. In: Annual technical meeting, 1988: OnePetro

Bennion D, Thomas F, Bennion D, Bietz R (995) Mechanisms of formation damage and permeability impairment associated with the drilling, completion and production of low API gravity oil reservoirs. In: SPE International Heavy Oil Symposium, 1995: Society of Petroleum Engineers

Morton EK, et al. (2005) Selection and evaluation criteria for highperformance drilling fluids. In: SPE Annual Technical Conference and Exhibition, 2005: OnePetro

Civan F (2007) Formation damage mechanisms and their phenomenological modeling-an overview. In: European formation damage conference, OnePetro

Al-Ani T, Sarapää O (2008) Clay and clay mineralogy. Physicalchemical properties and industrial uses

Mohsenzadeh A, Al-Wahaibi Y, Al-Hajri R, Jibril B, Joshi S, Pracejus B (2015) Investigation of formation damage by deep eutectic solvents as a new EOR agents. In: SPE European Formation damage conference and exhibition, 2015: OnePetro

Fink D, Rich C, Thomas G (1968) Determination of internal surface area, external water, and amount of montmorillonite in claywater systems. Soil Sci 105(2):71-77

Foster MD (1954) The relation between composition and swelling in clays. Clays Clay Mineral 3(1):205-220

Ghasemi H, Mozaffari S, Mousavi SH, Aghabarari B, Abu-Zahra N (2021) Decolorization of wastewater by heterogeneous Fenton reaction using $\mathrm{MnO} 2-\mathrm{Fe} 3 \mathrm{O} 4 / \mathrm{CuO}$ hybrid catalysts. J Environ Chem Eng 9(2):105091

Gkay D, Rex R (1966) Formation damage in sandstones caused by clay dispersion and migration," in Clays and Clay Minerals: Elsevier, pp. 355-366

Güçlü-Üstündağ Ö, Mazza G (2007) Saponins: properties, applications and processing. Crit Rev Food Sci Nutr 47(3):231-258

$\mathrm{He} \mathrm{Y}$ et al (2020) Synergy of imidazolium ionic liquids and flexible anionic polymer for controlling facilely montmorillonite swelling in water. J Mol Liq 317:114261

Ho TM, Howes T, Bhandari BR (2015) Characterization of crystalline and spray-dried amorphous $\alpha$-cyclodextrin powders. Powder Technol 284:585-594

Jahanbin K, Gohari AR, Moini S, Emam-Djomeh Z, Masi P (2011) Isolation, structural characterization and antioxidant activity of a new water-soluble polysaccharide from Acanthophyllum bracteatum roots. Int J Biol Macromol 49(4):567-572

Khayati H, Moslemizadeh A, Shahbazi K, Moraveji MK, Riazi SH (2020) An experimental investigation on the use of saponin as a non-ionic surfactant for chemical enhanced oil recovery (EOR) in sandstone and carbonate oil reservoirs: IFT, wettability alteration, and oil recovery. Chem Eng Res Design 160:417-425

Khilar KC, Fogler HS (1984) The existence of a critical salt concentration for particle release. J Colloid Interface Sci 101(1):214-224

Kulikova O, Mazlova E, Terekhova V, Karnaeva A, Malina N, Smirnova T (2021) Surfactant-enhanced treatment of oil-contaminated Arctic tundra soil: Ecotoxicological assessment. Environ Technol Innov 23:101570 
Kumar A, Mandal A (2017) Synthesis and physiochemical characterization of zwitterionic surfactant for application in enhanced oil recovery. J Mol Liq 243:61-71

Leroy P, Tournassat C, Bernard O, Devau N, Azaroual M (2015) The electrophoretic mobility of montmorillonite. Zeta potential and surface conductivity effects. J Colloid Interface Sci 451:21-39

Madsen FT, Müller-Vonmoos M (1989) The swelling behaviour of clays. Appl Clay Sci 4(2):143-156

Maria SF, Russell LM, Turpin BJ, Porcja RJ (2002) FTIR measurements of functional groups and organic mass in aerosol samples over the Caribbean. Atmos Environ 36(33):5185-5196

Mehrabianfar P, Malmir P, Soulgani BS, Hashemi A (2020) Study on the optimization of the performance of preformed particle gel (PPG) on the isolation of high permeable zone. J Pet Sci Eng 195:107530

Mehrabianfar P, Bahraminejad H, Manshad AK (2021) An introductory investigation of a polymeric surfactant from a new natural source in chemical enhanced oil recovery (CEOR). J Pet Sci Eng 198:108172

Mohan KK, Reed MG, Fogler HS (1999) Formation damage in smectitic sandstones by high ionic strength brines. Colloids Surf A Physicochem Eng Asp 154(3):249-257

Mooney R, Keenan A, Wood L (1952) Adsorption of water vapor by montmorillonite. II. Effect of exchangeable ions and lattice swelling as measured by X-ray diffraction. J Am Chem Soc 74(6):1371-1374

Moslemizadeh A, Shadizadeh SR, Moomenie M (2015) Experimental investigation of the effect of henna extract on the swelling of sodium bentonite in aqueous solution. Appl Clay Sci 105:78-88

Moslemizadeh A, Dehkordi AF, Barnaji MJ, Naseri M, Ravi SG, Jahromi EK (2016) Novel bio-based surfactant for chemical enhanced oil recovery in montmorillonite rich reservoirs: Adsorption behavior, interaction impact, and oil recovery studies. Chem Eng Res Design 109:18-31

Moslemizadeh A, Dezaki AS, Shadizadeh SR (2017) Mechanistic understanding of chemical flooding in swelling porous media using a bio-based nonionic surfactant. J Mol Liq 229:76-88

Moslemizadeh A, Samadzadeh Hafshejani K, Shahbazi K, Zaravi Dezfuli M, Zendehboudi S (2019) A biosurfactant for inhibiting clay hydration in aqueous solutions: applications to petroleum industry. Can J Chem Eng 97(1):384-394

Mozaffari S, Tchoukov P, Atias J, Czarnecki J, Nazemifard N (2015) Effect of asphaltene aggregation on rheological properties of diluted athabasca bitumen. Energy Fuels 29(9):5595-5599

Mozaffari S, Tchoukov P, Mozaffari A, Atias J, Czarnecki J, Nazemifard N (2017) Capillary driven flow in nanochannels-Application to heavy oil rheology studies. Colloids Surf A Physicochem Eng Asp 513:178-187

Mozaffari S, Ghasemi H, Tchoukov P, Czarnecki J, Nazemifard N (2021) Lab-on-a-chip systems in Asphaltene characterization: a review of recent advances. Energy Fuels 35:9080

Nikoobakht B, El-Sayed MA (2001) Evidence for bilayer assembly of cationic surfactants on the surface of gold nanorods. Langmuir 17(20):6368-6374

Nooripoor Vahid, Hashemi Abdolnabi (2020) Effect of a modified nano clay and nano graphene on rheology, stability of water-in-oil emulsion, and filtration control ability of oil-based drilling fluids: a comparative experimental approach. Oil Gas Sci Technol Revue d'IFP Energies nouvelles 75:40

Norrish K (1954) The swelling of montmorillonite. Discuss Faraday Soc 18:120-134

Nowrouzi I, Mohammadi AH, Manshad AK (2020) Primary evaluation of a synthesized surfactant from waste chicken fat as a renewable source for chemical slug injection into carbonate oil reservoirs. J Mol Liq 306:112843

Pal N, Samanta K, Mandal A (2019) A novel family of non-ionic gemini surfactants derived from sunflower oil: synthesis, characterization and physicochemical evaluation. J Mol Liq 275:638-653

Rezaei A, Shadizadeh SR (2021) State-of-the-art drilling fluid made of produced formation water for prevention of clay swelling: experimental Investigation. Chem Eng Res Design 170:350-365

T. M. Riddick TM (1968) Control of colloid stability through zeta potential: with a closing chapter on its relationship to cardiovascular disease. Published for Zeta-Meter, inc., by Livingston Pub. Co.

Rosen MJ, Kunjappu JT (2012) Surfactants and interfacial phenomena. Wiley, Hoboken

Salles F, Bildstein O, Douillard J-M, Jullien M, Van Damme H (2007) Determination of the driving force for the hydration of the swelling clays from computation of the hydration energy of the interlayer cations and the clay layer. J Phys Chem C 111(35):13170-13176

Sameni A, Pourafshary P, Ghanbarzadeh M, Ayatollahi S (2015) Effect of nanoparticles on clay swelling and migration. Egyptian J Pet 24(4):429-437

Shadizadeh SR, Moslemizadeh A, Dezaki AS (2015) A novel nonionic surfactant for inhibiting shale hydration. Appl Clay Sci 118:74-86

Sharifipour M, Pourafshary P, Nakhaee A (2017) Study of the effect of clay swelling on the oil recovery factor in porous media using a glass micromodel. Appl Clay Sci 141:125-131

Stamatakis E, Patel B, Young S (2007) High performance water based drilling mud and method of Use. US Patent, vol. 7250390, no. 16, pp. 49320-49328

Stanimirova R, Marinova K, Tcholakova S, Denkov N, Stoyanov S, Pelan E (2011) Surface rheology of saponin adsorption layers. Langmuir 27(20):12486-12498

Tesema TE, Kookhaee H, Habteyes TG (2020) Extracting electronic transition bands of adsorbates from molecule-plasmon excitation coupling. J Phys Chem Lett 11(9):3507-3514

Wilson M, Wilson L, Patey I (2014) The influence of individual clay minerals on formation damage of reservoir sandstones: a critical review with some new insights. Clay Minerals 49(2):147-164

Xing $\mathrm{Y}$ et al (2017) Recent experimental advances for understanding bubble-particle attachment in flotation. Adv Colloid Interf Sci 246:105-132

Zaltoun A, Berton N (1992) Stabilization of montmorillonite clay in porous media by high-molecular-weight polymers. SPE Product Eng 7(02):160-166

Zargar G, Mohsenatabar Firozjaii A, Khedri Mirghaed M, Moghadasi J (2021) Experimental study on preventing formation damage due to clay swelling caused by water based drilling fluid using aluminum ion based clay inhibitor. J Pet Sci Technol

Zhang L, Zhou F, Zhang S, Wang Y, Wang J, Wang J (2019) Investigation of water-sensitivity damage for tight low-permeability sandstone reservoirs. ACS Omega 4(6):11197-11204

Zhang K et al (2020) Digital twin-based opti-state control method for a synchronized production operation system. Robot Comput Integr Manuf 63:101892

Zhong H, Qiu Z, Huang W, Cao J (2011) Shale inhibitive properties of polyether diamine in water-based drilling fluid. J Pet Sci Eng 78(2):510-515

Publisher's Note Springer Nature remains neutral with regard to jurisdictional claims in published maps and institutional affiliations. 